\title{
ERRATUM
}

\section{Positive Psychology Interventions in Practice}

\section{Carmel Proctor}

(C) Springer International Publishing AG 2017

C. Proctor (ed.), Positive Psychology Interventions in Practice, DOI 10.1007/978-3-319-51787-2

DOI 10.1007/978-3-319-51787-2_16

Chapter 11 in: Suzy Green, Olivia Evans, and Belinda Williams, Positive Psychology at Work: Research and Practice, DOI 10.1007/978-3-319-51787-2_11.

The original version of this book was published with an additional affiliation for Dr. Suzy Green. It is removed and updated in the current version:

S. Green

The Positivity Institute, Level 57, MLC Centre, 19-29 Martin Place, Sydney, NSW 2000, Australia 